\title{
Spectroscopic investigation of Rhodamine-B thin film prepared by PLD technique
}

\author{
Adel Ch. Majeed ${ }^{1}$ and Ali A-K. Hussain ${ }^{2}$ \\ ${ }^{1}$ General Directorate of Education of Baghdad, Ministry of Education, Iraq \\ ${ }^{2}$ Department of Physics, College of Science, University of Baghdad, Iraq \\ E-mail: draliakh97@ scbaghdad.edu.iq
}

\begin{abstract}
Optical properties of Rhodamine-B thin film prepared by PLD technique have been investigated. The absorption spectra using $1064 \mathrm{~nm}$ and $532 \mathrm{~nm}$ laser wavelength of different laser pulse energies shows that all the curves contain two bands, B band and $\mathrm{Q}$ bands with two branches, $\mathrm{Q}_{1}$ and $\mathrm{Q}_{2}$ band and a small shift in the peaks location toward the long wavelength with increasing laser energy. FTIR patterns for Rhodamine-B powder and thin film within shows that the identified peaks were located in the standard values that done in the previous researches. X-ray diffraction patterns of powder and prepared Rhodamine-B thin film was display that the powder has polycrystalline of tetragonal structure, while the thin film has an amorphous structure. SEM images for Rhodamine-B, shows homogeneous distributed cauliflower-like nanostructures attached with each other. FM diagram shows that the average grain size was found to be $68.52 \mathrm{~nm}$ and the RMS surface roughness was $1.68 \mathrm{~nm}$.
\end{abstract} Key words

Rhodamine-B, Optical properties, PLD technique

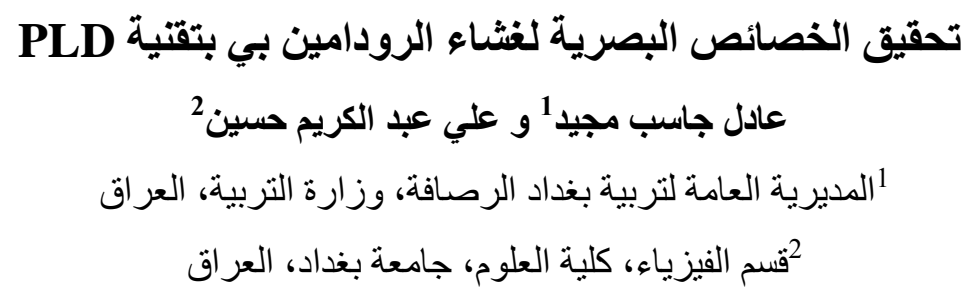

Article info.

Received: Sep. 2018

Accepted: Dec. 2018

Published: Mar. 2019

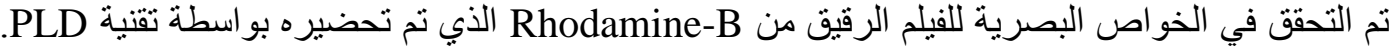

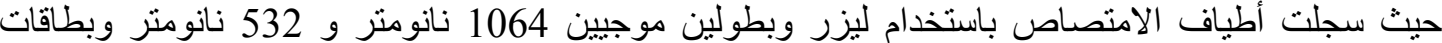

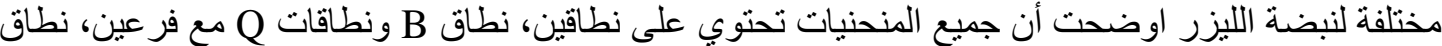

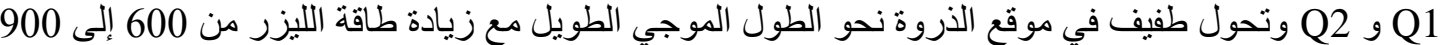

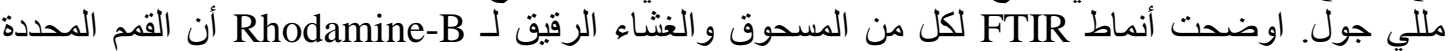

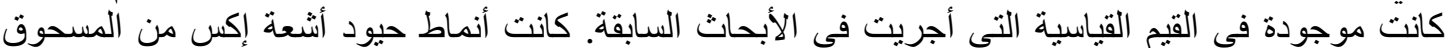

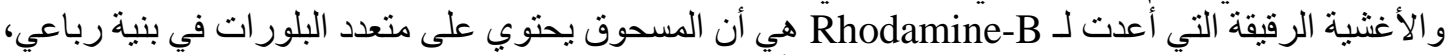

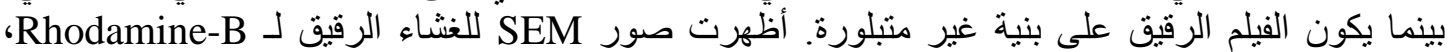

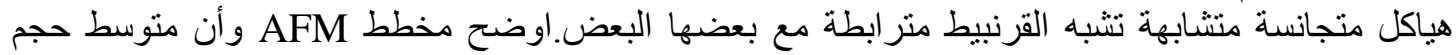
الحبيية كان 52.68 نانومتر وكان خشونة سطح 1.68 نانومتر.
}

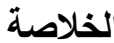




\section{Introduction}

Laser Induced Breakdown Spectroscopy (LIBS) is one of laser based methods that widely applied in material sciences [1]. LIBS was first suggested as an analytical tool back to 1962, during last two decades much improved in this method and several new applications have been introduced [2].

LIBS have been used in many applications; mainly due to its flexibility [3]. Field portable LIBS systems have been shown to be able to detect hazardous materials including bio aerosols $[4,5]$.

In laboratory uses range from industrial use (e.g.) as metallic alloy composition measurements, steel and glass melt testing, etc. $[6,7]$ to detection of bacteria and other pathogens, LIBS can be used to discriminate between different strains of the same bacteria [8].

The interaction of strong electromagnetic radiation fields with the electrons in a condensed medium with a band gap larger than the photon energy, nonlinear processes such as multiphoton ionization or the tunnel effect can lead to the generation of in the conduction band. A sufficient kinetic energy from the electric field can gained by these free electrons produce more free carriers by inverse Bremsstrahlung absorption through impact ionization [9].

Plasma formation because of the rapid ionization of the medium led to a great increase of the absorption coefficient, which caused a rise to a rapid energy transfer from the radiation field to the medium. when the free electron density exceeds a critical value of $108-1020 \mathrm{~cm}^{-3}$ laser induced breakdown is occur [10].

Breakdown can occur in one of two ways, multiphoton ionization or cascade ionization. In multiphoton ionization, two or more photons are absorbed simultaneously by the particle so that there is enough energy to ionize it. Because multiple photons are needed for ionization to occur, high irradiances are usually required [11].

Atomic processes within the plasma govern the manner in which radiation is absorbed, transported, or emitted from plasmas. The populations of different energy levels and the ionization stages in the plasma are the factors influencing this process [12].

Although it causes the damage of optical components in high power laser systems Laser-induced breakdown has been studied mainly in solids because of its importance. In recent years [13].

Rhodamine-B is one of the commonly used dyes widely used in industrial purposes, such as printing, paper, paints, leathers etc. The present promising application for the organic dye is a photocatalyst due to decomposition with superior activity. The incorporation of organic dyes into solid matrices has been a great deal of interest, because of useful applications such as light concentrators in solar cells, optical waveguides, laser materials, sensors, and nonlinear optical materials [14].

Rhodamine B is a xanthene widely used as an active medium in dye lasers, as a photosensitizer, and as a quantum counter [15]. The spectroscopic and photophysical properties of this dye have been extensively studied in different media $[16,17]$. there is little information on the optical properties of Rhodamine- B [18].

\section{Experimental part \\ 1. Materials}

Pure Rhadomine-B (99\%) was purchased from MERCK company, appearance red to violet powder, Chemical formula $\mathrm{C}_{28} \mathrm{H}_{31} \mathrm{ClN}_{2} \mathrm{O}_{3}$ and Molar mass $479.02 \mathrm{~g} \cdot \mathrm{mol}^{-1}$. 


\section{Sample preparation}

Samples were prepared in the form of pellets. Pressing $(2 \mathrm{~g})$ of material by hydraulic press operating (6-8) bar for $(15 \mathrm{~min})$ to get a pellet of $(20 \mathrm{~mm})$ in diameter and thickness of approximately $(5 \mathrm{~mm})$.

\section{Experimental Setup}

The set-up of PLD consists, vacuum chamber and laser system. A schematic diagram illustrates the experimental setup as shown in Fig.1.

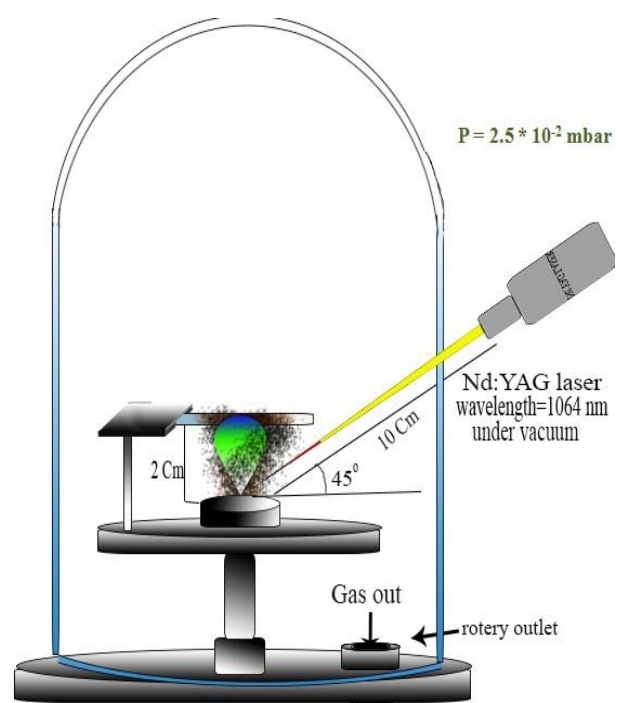

Fig.1: Schematic of the PLD experimental setup in plasma lap for higher studies.

PLD has been done inside the vacuum chamber at pressure $2.5 \times 10^{-2}$ mbar to cause the oxidizing of target materials.

In the present work Nd:YAG laser (Huafei Tongda Technology Diamond 288 pattern EPLS) is used. This device was consisting of power supply system, computer-controlling system, cooling system, and the light route system. The main laser system parameters are, Q-switched Nd:YAG model, wavelength of the first Harmonic oscillator $1064 \mathrm{~nm}$, Pulse energy (10-2000) mJ, Repetition Frequency (1-10) Hz, Laser pulse duration (9 ns), Laser peak power (636) $\mathrm{mW}$, and Pulse width (10 ns).

\section{Steps of PLD working}

The steps of PLD working as follows:

1) Laser beams of $1064 \mathrm{~nm}$ wavelength with different pulse energies (600, 700, 800 and 900) $\mathrm{mJ}$ are focused through a Pyrex glass window into the vacuum chamber at pressure $2.5 \times 10^{-2}$ mbar and hit the surface of the sample with angle $45^{0}$ to the normal of the surface during a 500 shots.

2) Amount of sample was ablated when the laser is focused onto the sample, it is extremely small, approximately Nano-grams.

3) The

films were deposited on glass or silicon at substrate.

4) Repeating the above steps using a laser source of $532 \mathrm{~nm}$ wavelength.

Several things must be taken into consideration during work. First is the substrate is placed in front of the target with sufficient distance (1-2.5) $\mathrm{cm}$ to avoid blocking the laser beam by the substrate holder and the second is that the target surface was rotated in order to expose a fresh surface after every train of shots; this reduced the possible effects of cratering e.g., plasma confinement and/or occlusion by the target surface formation.

\section{Results and discussion}

\section{UV-visible measurements}

The absorbance for Rhodamine-B thin films on glass substrate prepared by using $1064 \mathrm{~nm}$ and $532 \mathrm{~nm}$ laser wavelength at different laser energies were shown in Figs.2 and 3. Notice that all the curves contain two bands, B (at $308 \mathrm{~nm}$ ) and $\mathrm{Q}$ bands with two branches, $\mathrm{Q}_{1}$ band (at $521 \mathrm{~nm}$ ) and $\mathrm{Q}_{2}$ band (at $582 \mathrm{~nm}$ ).

The $\mathrm{Q}_{1}$ band is due to the transition between the bonding and anti-bonding $\left(\pi-\pi^{*}\right)$ at the dimer part, while the $\mathrm{Q}_{2}$ band corresponds to the absorption at 
the monomer part or as excitation peak, while B band are attributed to $\sigma$ conjugated bithiophene substitution [19]. $\mathrm{Q}_{1}$ and $\mathrm{Q}_{2}$ more distinguished for thin films prepared with high laser energy.

There is a small shift in the peaks location toward the long wavelength with increasing laser energy from 600 to $900 \mathrm{~mJ}$. Increasing laser energy cause to increase film thickness and crystalline size, so reduce the strain in lattice and reduce the bond energy. The absorbance peaks increased for B-band and Q-band and the absorption spectrum becomes wider.

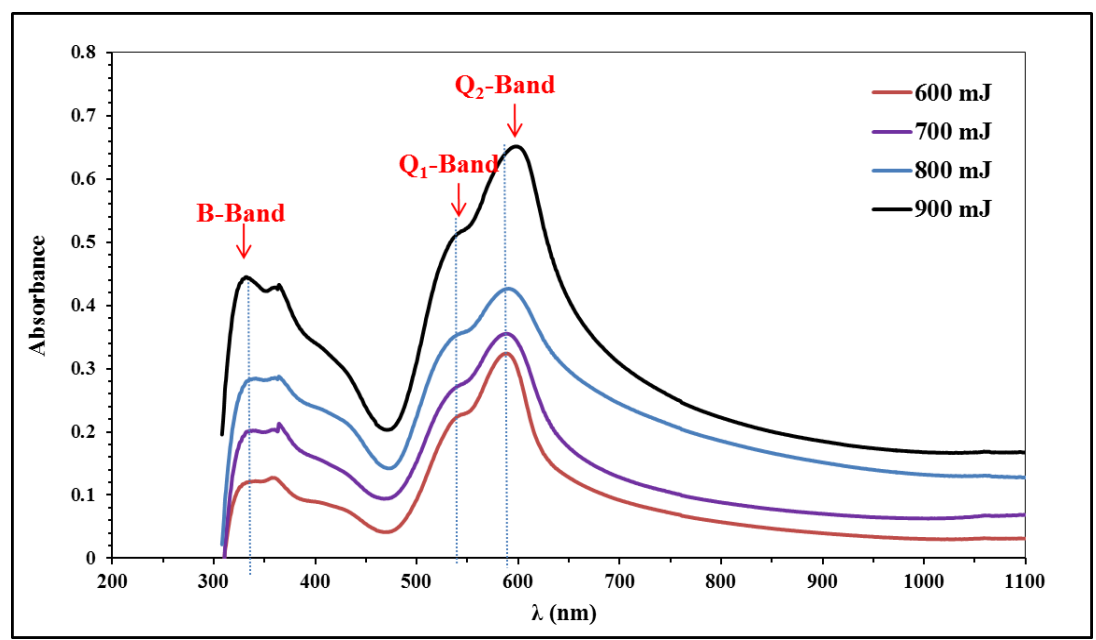

Fig.2: The absorbance for Rhodamine-B thin films deposited using $532 \mathrm{~nm}$ with different energies.

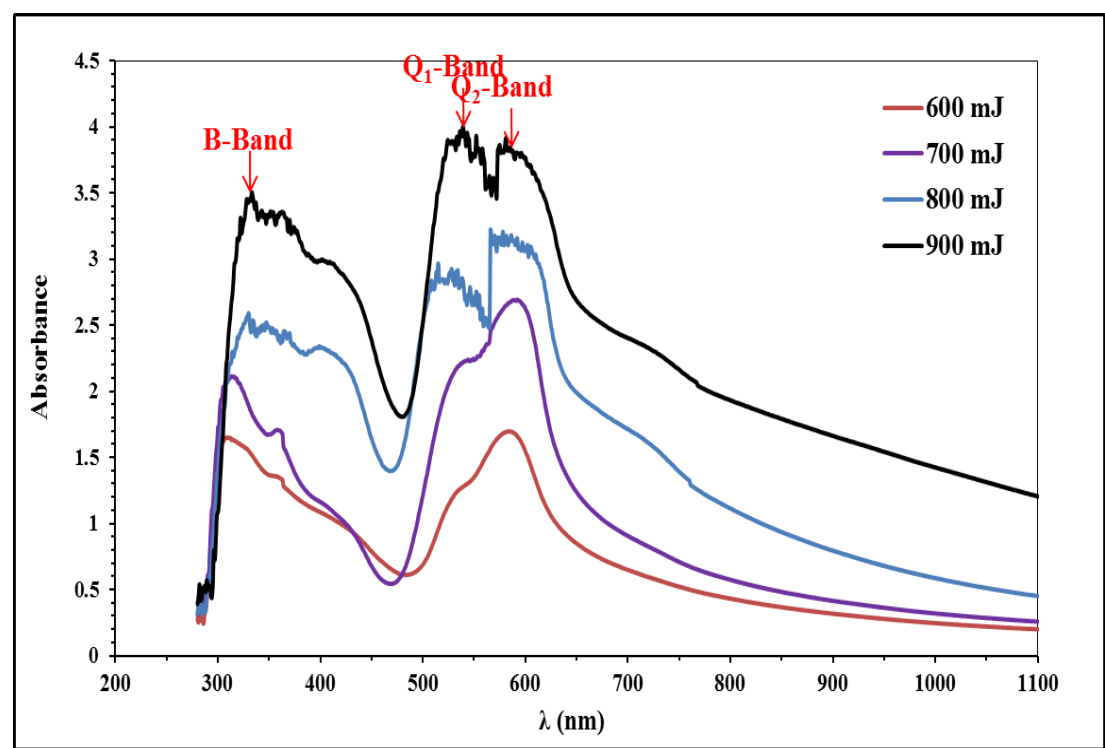

Fig.3: The absorbance for Rhodamine-B thin films deposited using $1064 \mathrm{~nm}$ laser with different energies.

By comparing the result using the two laser wavelengths, the peak position blue shifted when use $532 \mathrm{~nm}$ laser, due to increasing photon energy, which effected on deposited film structure.
Table 1 shows the bands data (wavelength and the optical energy gaps) for $\mathrm{B}$ and $\mathrm{Q}$ bands in Rhodamine-B thin films deposited using $1064 \mathrm{~nm}$ and $532 \mathrm{~nm}$ with different energies. 
Table 1: Bands position and the optical energy gaps for Rhodamine-B thin films deposited using $1064 \mathrm{~nm}$ and $532 \mathrm{~nm}$ with different energies.

\begin{tabular}{|c|c|c|c|c|c|c|}
\hline \multirow{2}{*}{$\begin{array}{c}\text { Laser } \\
\text { wavelength } \\
(\mathbf{n m})\end{array}$} & $\begin{array}{c}\text { Laser energy } \\
(\mathbf{m J})\end{array}$ & \multicolumn{3}{|c|}{ peak position (nm) } & \multicolumn{2}{c|}{ Eg (eV) } \\
\cline { 3 - 7 } & & B- band & Q1 - band & Q2 - band & Q band & B band \\
\hline \multirow{4}{*}{532} & 600 & 308 & - & 582 & 1.960 & 2.660 \\
\cline { 2 - 7 } & 700 & 313 & - & 587 & 1.940 & 2.640 \\
\cline { 2 - 7 } & 800 & 329 & 521 & 589 & 1.920 & 2.600 \\
\cline { 2 - 7 } & 900 & 333 & 538 & 589 & 1.840 & 2.520 \\
\hline \multirow{4}{*}{1064} & 600 & 337 & 543 & 586 & 1.960 & 2.520 \\
\cline { 2 - 7 } & 700 & 336 & 541 & 587 & 1.920 & 2.520 \\
\cline { 2 - 7 } & 800 & 335 & 541 & 589 & 1.860 & 2.520 \\
\cline { 2 - 7 } & 900 & 330 & 540 & 597 & 1.860 & 2.520 \\
\hline
\end{tabular}

\section{FTIR Measurements}

Fig.4 shows the FTIR patterns for Rhodamine-B powder and thin film within the range from 400 to $4000 \mathrm{~cm}^{-1}$, then focusing on the range 400 to $2000 \mathrm{~cm}^{-1}$. The identified peaks were located and matched with the standard values that done in the previous researches [20].

The two spectra show nearly same peaks located at 517.98, 581.01 for Metal bond, 681.21, 755.55, 816.97 for C-H meta-substitution, 920.40 for $\mathrm{C}-\mathrm{H}$ mono substitution, 1007.68 for $\mathrm{C}-\mathrm{O}$, 1075.56 for C-N, $1128.89,1178.99$ for $\mathrm{C}-\mathrm{O}, 1248.48,1272.73$ for $\mathrm{C}-\mathrm{OH}$ stretch, 1342.22 for C-H3 stretch, 1410.1 for C-H bend, 1474.75 for nitro, $1507.07,1550.71,1589.49,1642.83$ for $\mathrm{C}=\mathrm{C}$ aromatic, 1694.55 for $\mathrm{C}=\mathrm{N}$, $2873.15,2982.88$ for C-H stretch, 3413.36 for O-H.

In addition, this figure indicates that almost peaks has small shift toward less values for thin film sample. New peak appeared at $1752.73 \mathrm{~cm}^{-1}$ corresponding to $\mathrm{C}=\mathrm{O}$ band, while the $\mathrm{C}=\mathrm{N}$ peak disappeared, as shown in Table 2. All peaks between 681 and $3413 \mathrm{~cm}^{-1}$ corresponding to certain chemical bonds of Rhodamine-B.

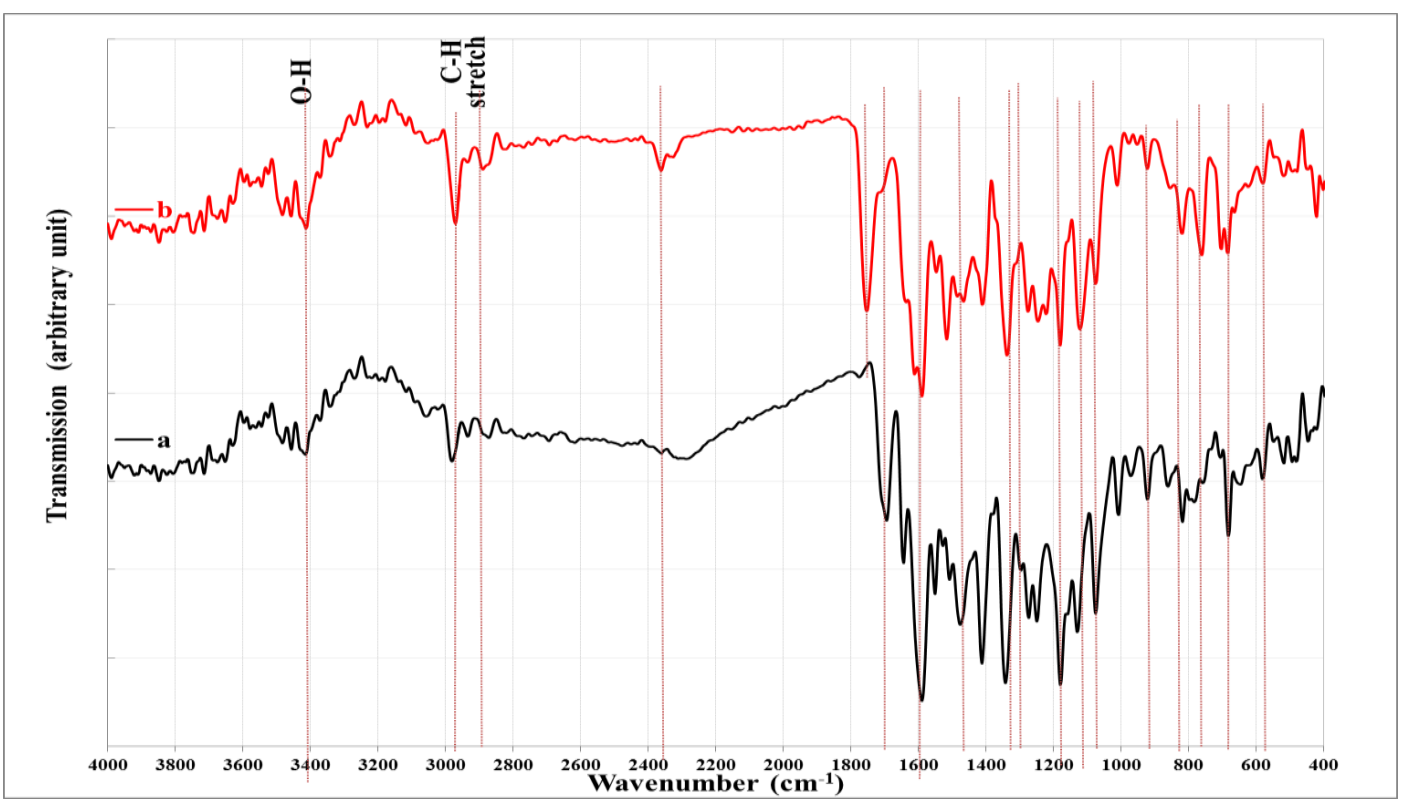

Fig.4: FTIR for Rhodamine-B (a) powder 


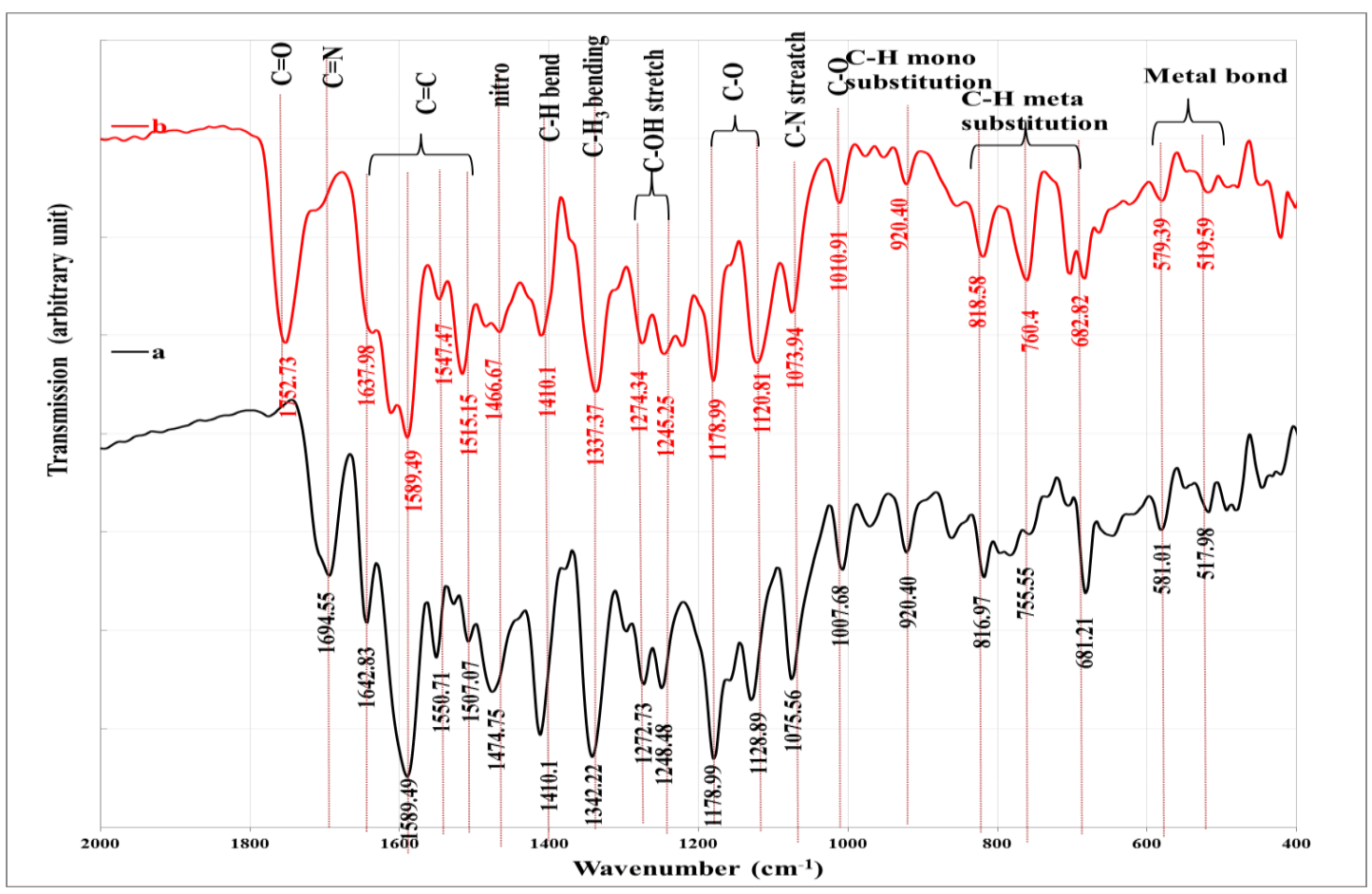

Fig.4: FTIR for Rhodamine-B (b) thin film.

Table 2: FTIR band for Rhodamine-B powder and thin film.

\begin{tabular}{|c|c|c|}
\hline & Powder & Thin film \\
\hline \multirow{2}{*}{ Metal bond } & 517.98 & 519.59 \\
\hline & 581.01 & 579.39 \\
\hline \multirow{3}{*}{$\mathrm{C}-\mathrm{H}$ meta substitution } & 681.21 & 682.82 \\
\hline & 755.55 & 760.40 \\
\hline & 816.97 & 818.58 \\
\hline $\mathrm{C}-\mathrm{H}$ mono substitution & 920.40 & 920.40 \\
\hline $\mathrm{C}-\mathrm{O}$ & 1007.68 & 1010.91 \\
\hline $\mathrm{C}-\mathrm{N}$ & 1075.56 & 1073.94 \\
\hline \multirow{2}{*}{$\mathrm{C}-\mathrm{O}$} & 1128.89 & 1120.81 \\
\hline & 1178.99 & 1178.99 \\
\hline \multirow{2}{*}{$\mathrm{C}-\mathrm{OH}$ stretch } & 1248.48 & 1245.25 \\
\hline & 1272.73 & 1274.34 \\
\hline C-H3 stretch & 1342.22 & 1337.37 \\
\hline C-H bend & 1410.1 & 1410.10 \\
\hline nitro & 1474.75 & 1466.67 \\
\hline \multirow{4}{*}{$\mathrm{C}=\mathrm{C}$} & 1507.07 & 1515.15 \\
\hline & 1550.71 & 1547.47 \\
\hline & 1589.49 & 1589.49 \\
\hline & 1642.83 & 1637.98 \\
\hline $\mathrm{C}=\mathrm{N}$ & 1694.55 & - \\
\hline $\mathrm{C}=\mathrm{O}$ & - & 1752.73 \\
\hline \multirow{2}{*}{ C-H stretch } & 2873.15 & 2890.04 \\
\hline & 2982.88 & 2970.22 \\
\hline $\mathrm{O}-\mathrm{H}$ & 3413.36 & 3413.36 \\
\hline
\end{tabular}




\section{X-Ray diffraction}

Fig.5 shows X-ray diffraction patterns of powder and prepared Rhodamine-B thin film using pulse laser deposition technique (PLD). The powder sample show polycrystalline of tetragonal structure identical with previous study [21], while thin film sample has amorphous structure.

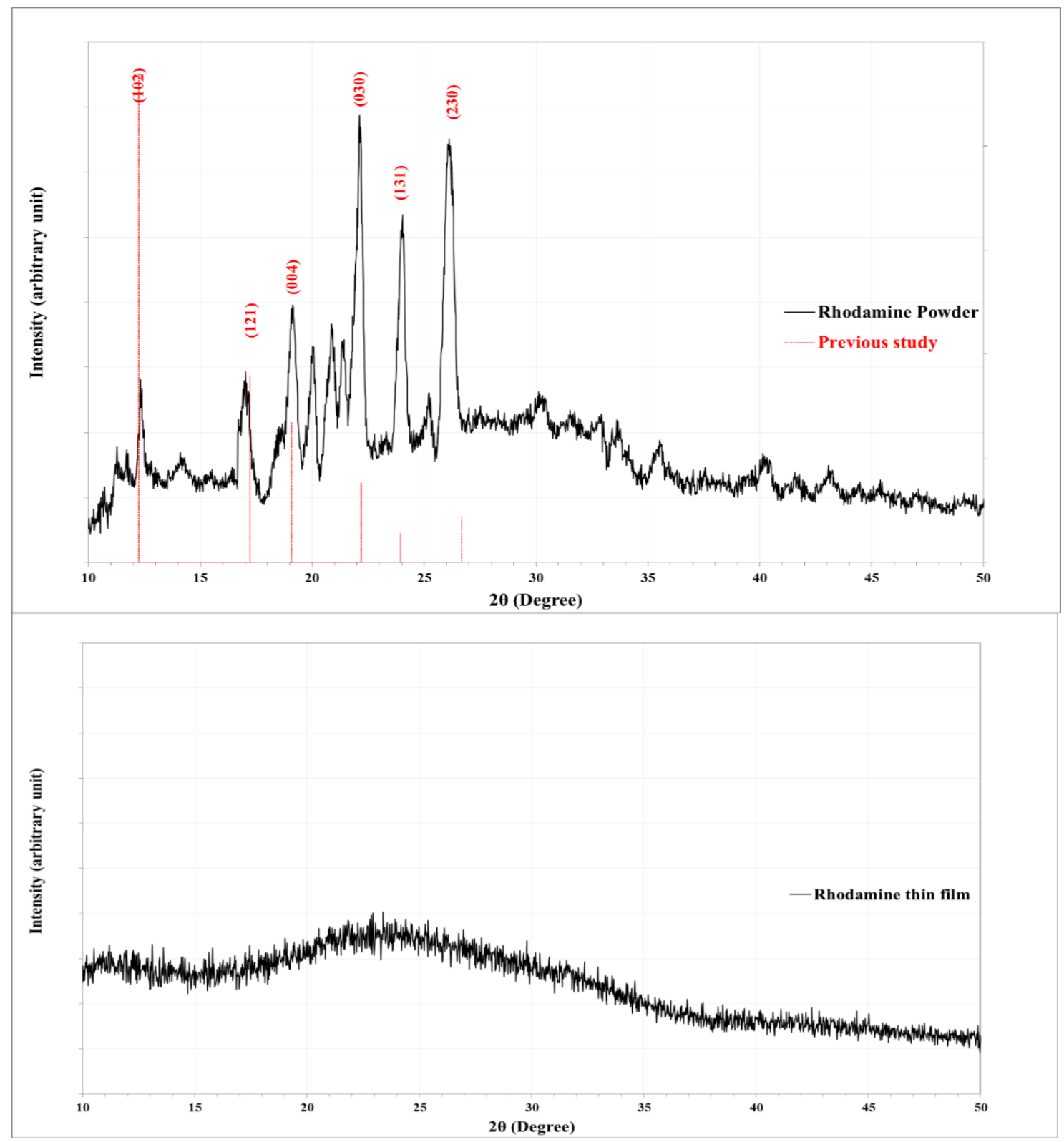

Fig.5: XRD for Rhodamine-B powder and thin film.

\section{4 -Scanning Electron Microscope} (SEM)

Fig.6 illustrates the SEM images for Rhodamine-B, thin films prepared by pulse laser deposition on glass substrate in three magnification powers $(\times 1 \mathrm{k}, \times 10 \mathrm{k}$ and $\times 50 \mathrm{k})$. The SEM image for Rhodamine-B shows homogeneous distributed cauliflowerlike nanostructures attached with each other. The sample surface has large surface area. 

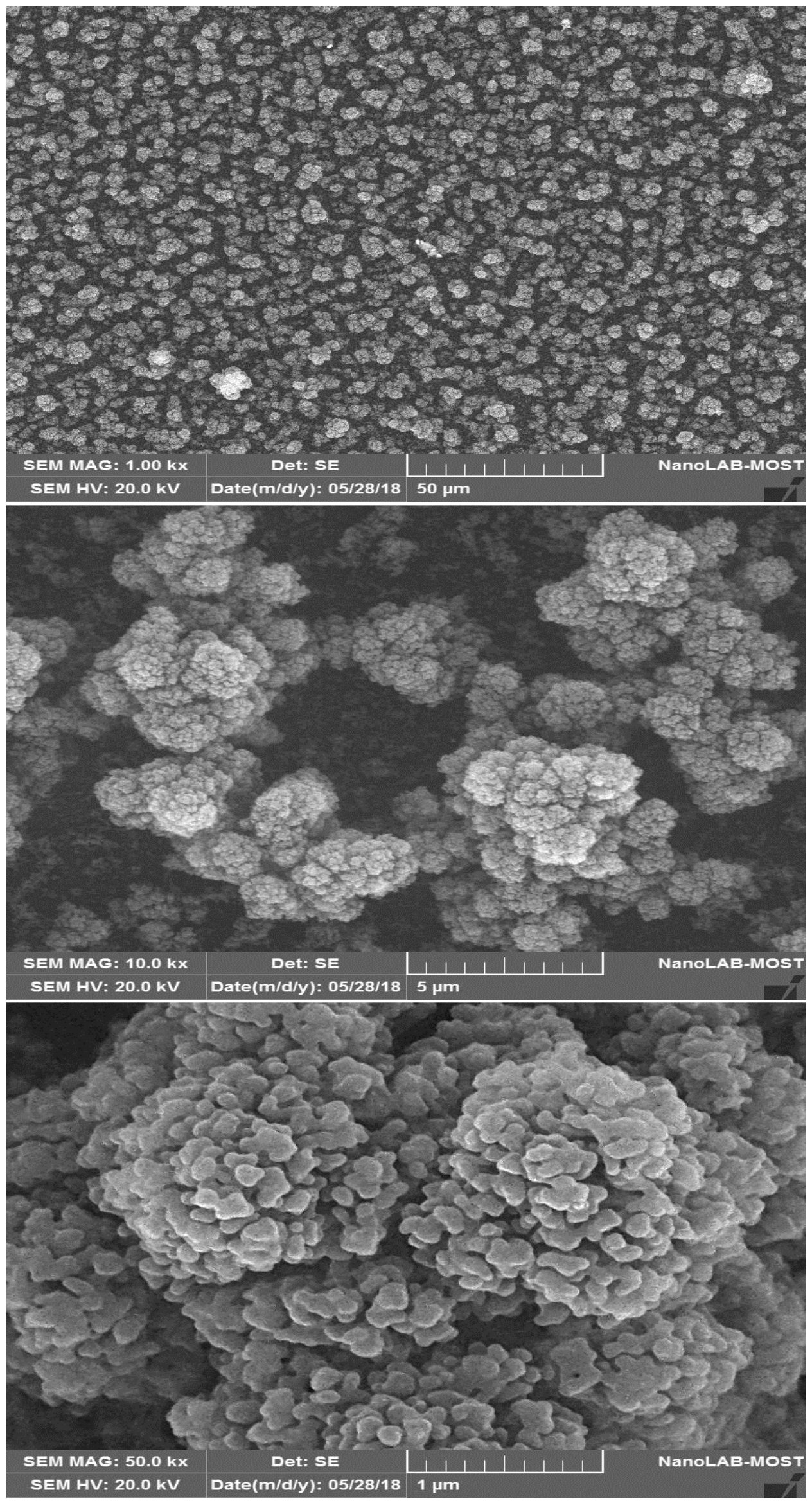

Fig.6: SEM image for Rhodamine-B with different magnification powers. 


\section{5 -Atomic Force Microscopy (AFM)}

Fig.7 illustrates the AFM diagram of the Rhodamine-B thin film and its granulating distribution. The average grain size was found to be $68.52 \mathrm{~nm}$ of the deposited thin films and the RMS surface roughness was $1.68 \mathrm{~nm}$.

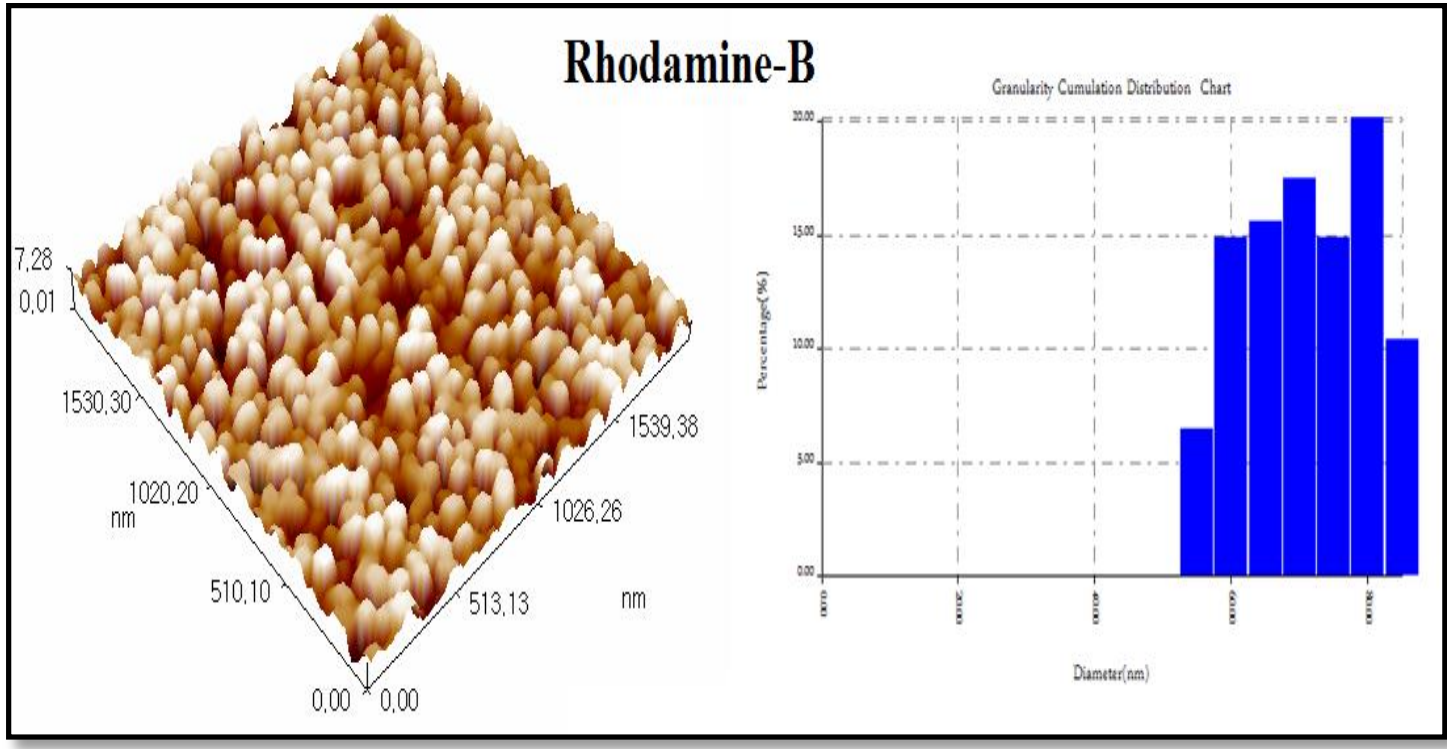

Fig.7: 3D AFM image and their granularity accumulation distribution for Rhodamine-B thin films.

\section{Conclusions}

Rhodamine-B nanoparticles have successfully been prepared using PLD technique at different laser energies, a small red shift of the absorption peak with increasing laser energy from 600 to $900 \mathrm{~mJ}$, film thickness and crystalline size are Increasing with increasing laser energy due to the decreasing the strain in lattice and reduce the bond energy. FTIR patterns for thin film display a new peak appeared at $1752.73 \quad \mathrm{~cm}^{-1}$ corresponding to $\mathrm{C}=\mathrm{O}$ band, while the $\mathrm{C}=\mathrm{N}$ peak disappeared, Thin film has a homogeneous nanostructures distribution cauliflower-like with a large surface area, which can be used in many applications.

\section{References}

[1] D. A. Cremers, Handbook of LaserInduced Breakdown Spectroscopy. USA: Wiley, 2013.

[2] M. Milán and J. J. Laserna,
Spectrochim. Acta - Part B At. Spectrosc., 56, 3 (2001) 275-288.

[3] A. W. Miziolek, V. Palleschi, I. Schechter, Laser Induced Breakdown Spectroscopy. Cambridge University Press, 2006.

[4] C. A. Munson, F. C. De Lucia, T. Piehler, K. L. McNesby, A. W. Miziolek, Spectrochim. Acta - Part B At. Spectrosc., 60, 7-8 (2005) 12171224.

[5] R. Zubrin, The Case For Mars. Simon \& Schuster UK, 2006.

[6] I. V. Cravetchi, M. Taschuk, Y. Y. Tsui, R. Fedosejevs, Spectrochim. Acta - Part B At. Spectrosc., 59, 9 (2005) 1439-1450.

[7] M. P. Mateo, S. Palanco, J. M. Vadillo, J. J. Laserna, Appl. Spectrosc., 54, 10 (2000) 1429-1434.

[8] DeLucia, F. C., Alan C. Samuels, Russell S. Harmon, Roy A. Walters, Kevin L. McNesby, Aaron LaPointe, R. J. Winkel, Andrzej W. Miziolek., 
IEEE Sens. J., 5, 4 (2005) 681-689.

[9] Y. R. Shen, The Principles of Nonlinear Optics. Wiley, 1984.

[10] R. F. Steinert and C. A. Puliafito, The Nd-YAG laser in ophthalmology: principles and clinical applications of photodisruption. Saunders, 1985.

[11] Radziemski, Lasers-Induced Plasmas and Applications. CRC Press, 1989.

[12] H. R. Griem, Principles of Plasma Spectroscopy. Cambridge University Press, 1997.

[13] M. R. Prince, G. M. Lamuraglia, P. Teng, T. F. Deutsch, R. R. Anderson, IEEE J. Quantum Electron., 23, 10 (1987) 1783-1786.

[14] X. . Han, J. Lin, R. . Xing, J. Fu, S. Wang, Mater. Lett., 57, 7 (2003) 1355-1360.

[15] P. C. Beaumont, D. G. Johnson, B. J. Parsons, J. Chem. Soc. Faraday Trans., 89, 23 (1993) 4185- 4191.
[16] F. L. Arbeloa, P. R. Ojeda, I. L. Arbeloa, J. Lumin., 44, 1-2 (1989) 105-112.

[17] I. L. Arbeloa and P. R. Ojeda, Chem. Phys. Lett., 79, 2 (1981) 347350 .

[18] B. Pettinger, K. Krischer, G. Ertl, Chem. Phys. Lett., 151, 1-2 (1988) 151-155.

[19] S. Cogal, K. Ocakoglu, A. U. Oksuz, Inorganica Chim. Acta, 423, Part A (2014) 139-144.

[20] A. Frank, Handbook of instrumental Techniques for analytical chemistry. Prentice Hall Inc PTR, 1997.

[21] A. A. M. Farag and I. S. Yahia, Synth. Met., 161, 1-2 (2011) 32-39. 